\title{
Reconstruction of Large Defect of Foot with Extensive Bone Loss Exclusively Using a Latissimus Dorsi Muscle Free Flap: A Potential New Indication for This Flap
}

\author{
Manuel Macemino Gomez, MD ${ }^{1}$, Diogo Casal, $\mathrm{MD}^{2}$ \\ ${ }^{1}$ Physician, Department of Plastic and Reconstructive Surgery, São Bernardo Hospital, Setúbal, Portugal \\ ${ }^{2}$ Physician, Department of Plastic and Reconstructive Surgery, São José Hospital, Lisbon, Portugal
}

A R T I C L E I N F O

\section{Level of Clinical Evidence: 4}

Keywords:

bone graft

injury

limb salvage

microsurgery

surgery

trauma

\begin{abstract}
A B S T R A C T
In cases of extensive damage to the foot, with significant bone loss, it is generally accepted that reconstruction must include bone flaps or grafts either in the emergency setting or subsequently. In this report, we describe the case of an 18-year-old student with an avulsion injury of the dorsum of his right foot. Consequently, he lost most of the soft tissue over the dorsum of the foot and the cuboid, navicular, and cuneiform bones. A latissimus dorsi free flap was used to reconstruct the defect. A functional pseudoarthrosis developed between the remaining bones of the foot, and the patient experienced satisfactory foot function after rehabilitation. For this reason, no additional reconstructive procedure was undertaken. This case suggests that it might be adequate to use the latissimus dorsi muscle flap more liberally than previously reported in the reconstruction of extensive defects of the dorsum of the foot, including cases with significant bone loss. This option could avoid the morbidity and inconvenience of a second surgery and the need to harvest a bone flap or graft.
\end{abstract}

(c) 2012 by the American College of Foot and Ankle Surgeons. All rights reserved.
Since the beginning of the 1980s, microsurgical options have been increasingly used to reconstruct severe and extensive injuries of the foot that would otherwise lead to primary amputation (1-4). In this setting, several criteria determine the choice of the flap to be used in reconstruction, including donor site morbidity, length of the pedicle, and the extent and composition of the missing tissue $(2,5)$. In particular, it is generally accepted that significant bone defects should be treated with bone flaps or grafts, either in the emergency department or subsequently (2,4-9). In the present report, we describe the unusual case of a young male patient who sustained extensive soft tissue and bone injury to his foot and who responded well to treatment using a single-stage latissimus dorsi free flap without the use of bone grafting.

\section{Case Report}

An 18-year-old college student experienced an avulsion injury of the dorsum of his right foot and distal portion of the leg after

Financial Disclosure: None reported.

Conflict of Interest: None reported.

Address correspondence to: Manuel Macemino Gomez, MD, Physician, Department of Plastic and Reconstructive Surgery, São Bernardo Hospital, Rua Marconi 26 Linda a Velha 2795-135 Portugal.

E-mail address: maxgomez@sapo.pt (M.M. Gomez).

Video online only at http://www.jfas.org a motorcycle accident (Fig. 1). As a result, he had lost most of the soft tissue over the dorsum of the foot and nearly all the cuboid, navicular, and cuneiform bones. The patient was fully conscious on admission to the hospital and adamantly expressed his wish not to have his injured foot amputated. Therefore, the unviable tissues were carefully debrided, and a latissimus dorsi muscle free flap was used to obliterate the dead space and cover the dorsum of the foot (Fig. 2). The flap was anastomosed to the anterior tibial vessels. To stabilize the flap, the tarsal-metatarsal transition, and the ankle, Steinmann pins were used. Eight hours after the surgery, flap malperfusion was noted. On re-exploration, a thrombus inside the arterial anastomosis was noted. The thrombus was removed, and the anastomosis was performed slightly more proximally. The flap subsequently survived uneventfully. Two weeks after this procedure, the flap was covered with a split-thickness skin graft, which took completely. Six weeks after the initial surgery the Steinmann pins were removed, and the patient progressively resumed his daily activities. In the first year after surgery, the flap gradually decreased in bulk. Simultaneously, it regained some muscular tension, which helped stabilize the foot and seemed to play an active role in dorsiflexion (see Supplemental Video S1, available at www.jfas.org). Radiographically, a functional pseudoarthrosis had developed between the talus and the calcaneus and the metatarsal bones. Because the patient had a stable coverage of the foot and was able to walk normally in a regular shoe (Fig. 3 and Supplemental Video S1), no additional reconstructive procedure 


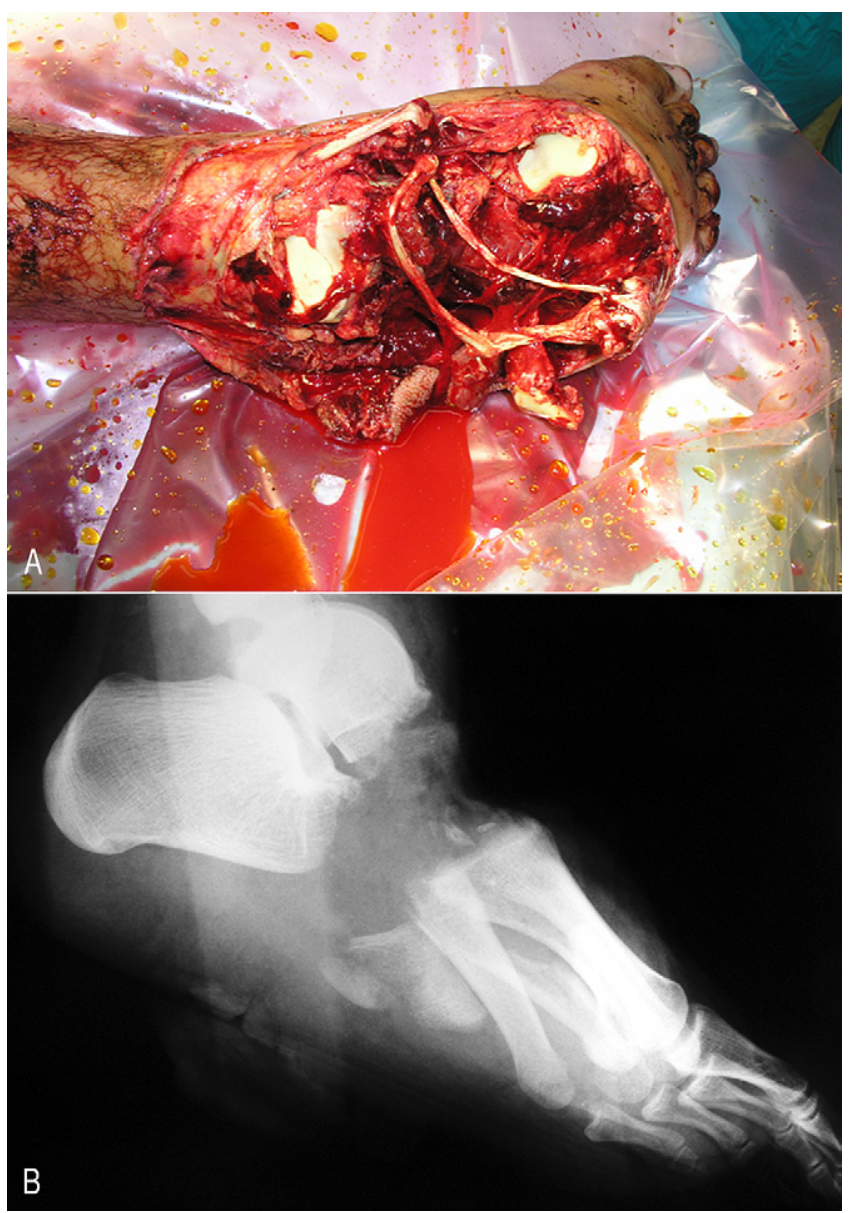

Fig. 1. (A) Severe injury to dorsum of right foot with extensive soft tissue and bony defect. $(B)$ Lateral radiograph of foot showing loss of most of navicular, cuboid, and cuneiform bones.

was proposed. At the latest follow-up visit, 59 months after the operation, the patient continued to ambulate well and to perform his regular activities in a fashion consistent with his preinjury status.

\section{Discussion}

According to the literature review we conducted, using the electronic biomedical databases, this is the first published report of a latissimus dorsi muscle flap used to obliterate the dead space associated with significant bony defects of the foot and to promote formation of a functional pseudoarthrosis (10-12). One of the main reasons for the satisfactory outcome observed in this case might be that the region of the bony defect in this patient does not normally bear much weight compared with the heel or the ball of the foot (2). In fact, it is well known that normally the weight-bearing points of the foot are the calcaneus and the 5 metatarsal heads $(13,14)$, all of which were preserved in this patient. The navicular, cuboid, and cuneiform bones, as well as the proximal part of the metatarsals, supported by the tick plantar and dorsal ligaments, the plantar aponeurosis, and the short plantar muscles, act mainly by distributing the weight between the weight-bearing areas of the foot (13-15). In addition, from a functional viewpoint, in our patient, the most seriously affected joint was the transverse tarsal joint, where the midfoot and forefoot rotate as an unit on the rearfoot, increasing the amplitude of the inversion and eversion movements occurring at the subtalar joint $(13,15)$. Because the latter joint was mostly

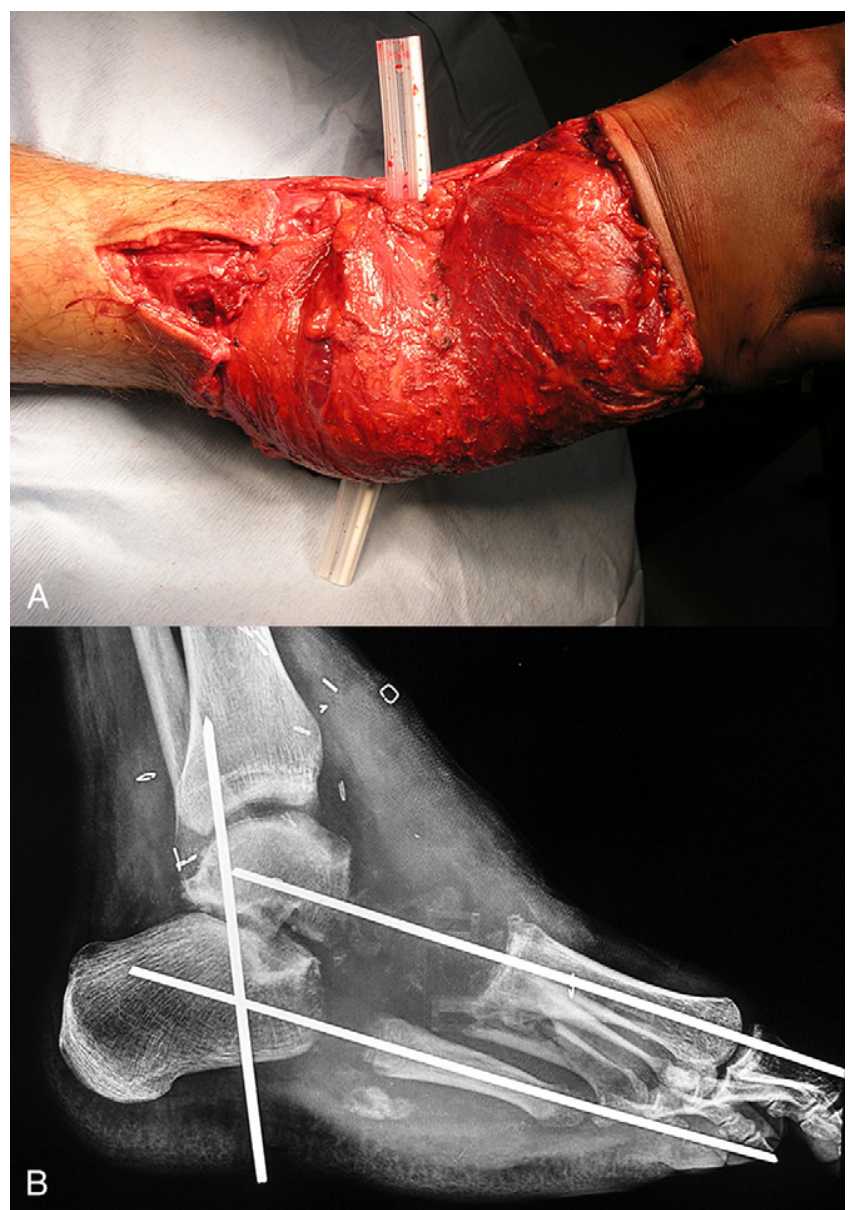

Fig. 2. (A) Postoperative view after debridement of unviable tissues and obliteration of dead space with latissimus dorsi muscle free flap. $(B)$ Postoperative lateral radiograph of foot with 2 Steinmann pins extending from first and fifth metatarsals to talus and calcaneus, respectively; another Kirschner wire was placed across calcaneus and talus, reaching distal portion of tibia.

preserved in our patient, the latissimus dorsi flap was able to transmit the inversion and eversion movements to the forefoot (Supplemental Video S1). Hence, the pseudoarthrosis that developed in this patient did not substantially affect the function of the foot and was relatively well tolerated both statically and dynamically (Supplemental Video S1). Therefore, this case seems to suggest that complex defects of this region of the foot can be reconstructed in a single reconstructive procedure using a latissimus dorsi muscle flap. This option would avoid the morbidity and inconvenience of a second surgery and the need of harvesting a bone flap or graft. Moreover, in any case, if the entire foot cannot be maintained, coverage of the distal portion of the stump will be facilitated by the presence of the well-vascularized latissimus dorsi muscle flap (16).

However, we are fully aware that large bony defects in the midfoot could become associated with foot instability, pain, and the loss of foot function (2). In these cases, functional reconnection between the rearfoot and the remainder of the midfoot and forefoot can be attempted with the use of foot orthoses, or, if these fail, with skeletal reconstruction techniques (8). These range from surgical arthrodeses (with or without autogenous or allogeneic bone grafts) to bone free flaps $(3,7)$. Among the various sources of vascularized bone, the iliac, fibular, and flaps are considered the most adequate in this setting (7). However, the unusual case we have described in this report serves to make clear that a free latissimus dorsi flap can be considered for use, in conjunction with Steinmann pin transfixation, to cover and 


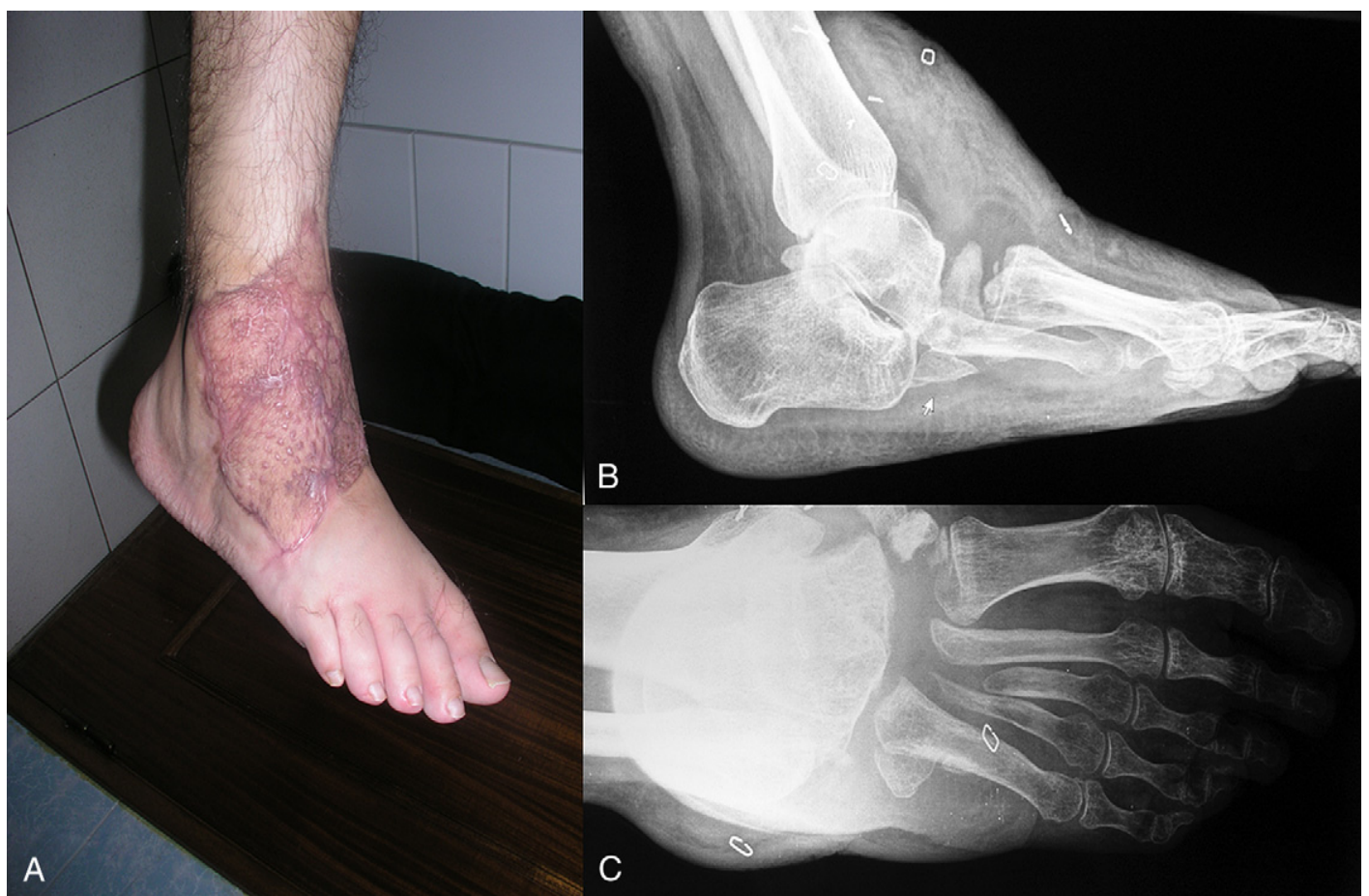

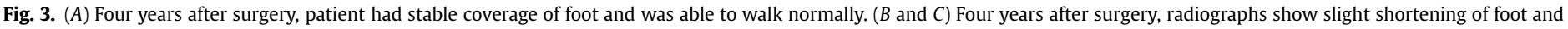
development of pseudoarthrosis between talus and calcaneus and metatarsal bones.

stabilize the foot after the traumatic loss of substantial amounts of bone and soft tissue.

\section{Supplementary Material}

Supplementary material associated with this article can be found in the online version at www.jfas.org (doi:10.1053/j.jfas.2011.07.008).

\section{References}

1. Frykman GK, Jobe CM. Amputation salvage with microvascular free flap from the amputated extremity. J Trauma 27:326-329, 1987.

2. Mackenzie DJ, Seyfer AE, Harvey EJ, Levin LS, Colen L, Uroskie T Jr. Reconstructive surgery: lower extremity coverage; skeletal reconstruction; foot reconstruction. In Plastic Surgery, pp 1355-1453, edited by SJ Mathes, Saunders, Philadelphia, 2006

3. Ong YS, Levin LS. Lower limb salvage in trauma. Plast Reconstr Surg 125:582-588, 2010.

4. Wettstein R, Schurch R, Banic A, Erni D, Harder Y. Review of 197 consecutive free flap reconstructions in the lower extremity. J Plast Reconstr Aesthet Surg 61:772776, 2008.

5. Korompilias AV, Lykissas MG, Vekris MD, Beris AE, Soucacos PN. Microsurgery for lower extremity injuries. Injury 39(Suppl 3):S103-S108, 2008.

6. Wu SP, Zhang FH, Yu FB, Zhou R. Medial malleolus and deltoid ligament reconstruction in open ankle fractures with combination of vascularized fibular head osteo-tendinous flap and free flap transfers. Microsurgery 29:630-635, 2009.
7. Yazar S, Lin $\mathrm{CH}$, Wei FC. One-stage reconstruction of composite bone and softtissue defects in traumatic lower extremities. Plast Reconstr Surg 114:14571466, 2004.

8. Yajima $\mathrm{H}$, Tamai S, Kobata $\mathrm{Y}$, Murata $\mathrm{K}$, Fukui A, Takakura Y Vascularized composite tissue transfers or open fractures with massive soft-tissue defects in the lower extremities. Microsurgery 22:114-121, 2002.

9. Banerjee R, Waterman B, Nelson J. Reconstruction of massive midfoot bone and soft tissue loss as a result of blast injury. J Foot Ankle Surg 49:301-304, 2010.

10. May JW Jr, Halls MJ, Simon SR. Free microvascular muscle flaps with skin graft reconstruction of extensive defects of the foot: a clinical and gait analysis study. Plast Reconstr Surg 75:627-641, 1985.

11. Ulucay GE, Yildirim S, Aydogdu E, Akoz T. Reconstruction of crush injuries of the foot dorsum: is the latissimus dorsi muscle flap a reliable choice? J Reconstr Microsurg 22:157-166, 2006.

12. Isik S, Celikoz B, Demirogullari M, Sengezer M, Selmanpakoglu N. Repair of highenergy-induced tissue defects of the dorsal foot by free muscle transfer and skin graft. Ann Plast Surg 43:21-29, 1999.

13. Colen L, Uroskie T Jr. Foot reconstruction. In Plastic Surgery, pp 1403-1453, edited by SJ Mathes, Saunders, Philadelphia, 2006.

14. Manter JT. Distribution of compression forces in the joints of the human foot. Anat Rec 96:313-321, 1946

15. Moore KL, Dalley A. Foot joints. In Clinically Oriented Anatomy, pp 707-724, edited by KL Moore, AF Dalley, Lippincott, Williams \& Wilkins, Philadelphia, 2006.

16. Hallock GG. Preservation of lower extremity amputation length using muscle perforator free flaps. J Plast Reconstr Aesthet Surg 61:643-647, 2008 